\title{
Roux-en-Y Drainage of the Pancreatic Stump Decreases Pancreatic Fistula After Distal Pancreatic Resection
}

\author{
M. Wagner • B. Gloor • M. Ambühl • M. Worni • \\ J. A. Lutz • E. Angst • D. Candinas
}

Published online: 28 February 2007

(C) 2007 The Society for Surgery of the Alimentary Tract

\begin{abstract}
Clinically relevant fistula after distal pancreatic resection occurs in 5-30\% of patients, prolonging recovery and considerably increasing in-hospital stay and costs. We tested whether routine drainage of the pancreatic stump into a Rouxen-Y limb after distal pancreatic resection decreased the incidence of fistula. From October 2001, data of all patients undergoing pancreatic distal resection were entered in a prospective database. From June 2003 after resection, the main pancreatic duct and the pancreatic stump were oversewn, and in addition, anastomosed into a jejunal Roux-en-Y limb by a single-layer suture $(n=23)$. A drain was placed near the anastomosis, and all patients received octreotide for 5-7 days postoperatively. The volume of the drained fluid was registered daily, and concentration of amylase was measured and recorded every other day. Patient demographics, hospital stay, pancreatic fistula incidence ( $\geq 30 \mathrm{ml}$ amylase-rich fluid/day on/after postoperative day 10), perioperative morbidity, and follow-up after discharge were compared with our initial series of patients (treated October 2001-May 2003) who underwent oversewing only $(n=20)$. Indications, patient demographics, blood loss, and tolerance of an oral diet were similar. There were four (20\%) pancreatic fistulas in the "oversewn" group and none in the anastomosis group $(p<0.05)$. Nonsurgical morbidity, in-hospital stay, and follow-up were comparable in both groups.
\end{abstract}

Keywords Distal pancreatic resection · Pancreatic fistula . Roux-en-Y anastomosis $\cdot$ Morbidity

\section{Introduction}

Pancreatic distal resection is a standardized procedure for the resection of lesions localized to the left of the portal vein. Despite advances in surgery during the last two decades, leakage from the pancreatic remnant after distal pancreatectomy presents a persistent problem. ${ }^{1,2}$ Thus, the incidence of postoperative pancreatic fistulas varies between 5 and $30 \%$ in recent studies. ${ }^{3-10}$ Various techniques

Wagner and Gloor both contributed equally in this work.

M. Wagner · B. Gloor $(\bowtie) \cdot$ M. Ambühl $\cdot$ M. Worni · J. A. Lutz

E. Angst $\cdot$ D. Candinas

Department of Visceral and Transplantation Surgery,

Inselspital, University of Bern,

Murtenstr., CH-3010, Bern, Switzerland

e-mail: beat.gloor@insel.ch are used for closure of the pancreatic remnant, such as ligation of the pancreatic duct followed by closure of the pancreatic stump with or without a serosa patch or closure using a stapling device. ${ }^{6,11-14}$ Interestingly, even when an identical technique was used, the reported incidence of fistulas varies widely. ${ }^{15}$ This variation may be attributable to differences in the definition of "pancreatic fistula" but also to technical variabilities within groups of "identical" stump closure and to the heterogeneity of patient populations. ${ }^{16}$

Importantly, a recent study found that complications derived from pancreatic fistulas after distal pancreatectomy doubled the cost and dramatically increased health-care resource use. ${ }^{2}$ Therefore, strategies are urgently needed that aid in reduction of the incidence of postoperative pancreatic fistulas, and thus, may decrease direct treatment costs. A retrospective survey found that draining the pancreatic remnant into an excluded loop of jejunum was only used sporadically. ${ }^{17,18}$ We therefore tested the hypothesis that routine drainage of the pancreatic stump into a Roux-en-Y limb may decrease the fistula rate after pancreatic distal resection. 


\section{Patients and Methods}

From October 2001, all patients undergoing pancreatic surgery were enrolled in a prospective data registry. Patients underwent a standardized preoperative evaluation consisting of contrast-enhanced abdominal computed tomography or magnetic resonance imaging. In selected patients, endoscopic retrograde cholangio- and pancreatography was performed. In patients in whom cancer was suspected, resection was performed in the absence of hematogenous metastases and when no gross retroperitoneal neoplastic or complex vascular infiltration was evident. Surgery consisted of an en-bloc pancreatic left resection, together with the spleen and the adjacent lymphatic tissue in all these patients. The extension of the cancer into the body of the pancreas determined the amount of tissue that was resected. In patients with chronic pancreatitis, the indications for surgery were intractable pain, alteration of the left-sided pancreas (e.g., pseudocysts), duct stenosis, pancreatic stones, or suspicion of cancer. In these patients, the spleen was conserved whenever technically feasible.

From October 2001 to May 2003, stump closure for pancreatic distal resection was accomplished by closing the pancreatic duct with interrupted prolene sutures followed by oversewing the pancreatic stump, cut in a fish-tail-like fashion, with a second layer of interrupted sutures using a resorbable, atraumatic suture material (PDS, Ethicon, Switzerland).

From June 2003, a modification was applied consisting of suturing the pancreatic stump as described above followed by an end-to-side pancreatico-jejunostomy into a retrocolic Roux-en-Y limb with a length of at least $30 \mathrm{~cm}$. The jejunum was opened slightly smaller than the diameter of the pancreas, and the anastomosis was performed in a capsule-to-mucosa fashion using a single layer resorbable, monofilament suture with interrupted stitches (PDS, Ethicon, Switzerland). A drain was placed near the anastomosis in all patients, and octreotide was administered for 5-7 days postoperatively $(3 \times 0.2 \mathrm{mg}$ s.c. daily). All patients received, perioperatively, a single-dose antibiotic prophylaxis (amoxicillin and clavulanic acid, GlaxoSmithKline, Switzerland). Empiric antibiotic treatment was continued after surgery in patients with manifest infections until resistance probes were received or the clinical presentation ameliorated.

Postoperatively, patients were cared for in the intensive or intermediate care unit as needed. Fluid was given intravenously, and patients were allowed to drink fluids depending on the operative procedure and clinical presentation. Solid foods were administered according to gastrointestinal (GI) function using a stepwise dietary regimen. Abdominal drainage volume was registered daily, and the amylase concentration of drained fluid was measured and recorded every other day. Patient demo- graphics, duration of hospital stay, incidence of pancreatic fistula, perioperative morbidity, and follow-up after discharge were recorded and compared with our previous series of patients in whom the pancreatic remnant was oversewn only. A pancreatic fistula was defined as secretion of at least $30 \mathrm{ml}$ of amylase-rich fluid (more than $5,000 \mathrm{U} / \mathrm{l}$ ) per day on or after the tenth postoperative day. Mortality was defined as the total in-hospital death rate. A biliary fistula was diagnosed if bilirubin-rich fluid was drained for more than 5 days. Bleeding was defined as the need for more than two units of packed red blood cells more than $24 \mathrm{~h}$ after operation or the need for reoperation for bleeding.

All variables were analyzed using the Fisher's exact test, $\chi^{2}$ test, and Mann-Whitney $U$ test, where appropriate, using SPSS Statistical Software (Chicago, IL, USA). All quantitative data are reported as median values and ranges. Differences at $P<0.05$ were considered statistically significant.

After discharge, all patients were seen in our outpatient clinic at least once. Thereafter, follow-up was registered using a standardized questionnaire, and patients were contacted by phone.

\section{Results}

A total of 44 pancreatic distal resections were performed during the study period. One patient who underwent emergency pancreatic distal resection because of a rupture of the pancreas after blunt abdominal trauma was excluded from the analysis. The remaining 43 patients were included. A total of 23 patients underwent distal resection with a pancreatico-jejunostomy, and 20 patients underwent stump closure by simple suturing of the pancreatic remnant. Demographic characteristics are summarized in Table 1 and were comparable between the two groups. The histologic classification and the range of surgical treatments are shown in Table 2. A neoplasm was found in 74 and $85 \%$ of patients, respectively (group "anastomosis" vs "oversewn"). Mean operative time was $345 \mathrm{~min}$ after pancreatico-jejunostomy vs $305 \mathrm{~min}$ after "oversewing" only; $p=0.329$. Duration until solid food intake was tolerated and duration of hospital stay (group 1: 13 days vs group 2: 16 days; $p=0.325)$ was comparable between groups. Drains were removed after a mean duration of 6 days in both groups $(p=0.5)$.

Postoperative morbidity is listed in Table 3. After pancreatico-jejunostomy, one patient had to be reoperated because of intra-abdominal bleeding in the region of the gastro-duodenal artery. Subsequently, this patient developed an intra-abdominal abscess caused by a localized necrosis in the pancreatic head and was treated by percutaneous drainage (amylase concentration of the drain fluid $<220 \mathrm{U} / \mathrm{l}$ ). 
Table 1 Demographics in Patients Undergoing Pancreatic Distal Resection $(n=43)$

\begin{tabular}{|c|c|c|c|}
\hline Clinical Data & $\begin{array}{l}\text { Group } 1(n=23) \\
\text { (with Pancreaticojejunostomy) }\end{array}$ & $\begin{array}{l}\text { Group } 2(n=20) \\
\text { (No Anastomosis) }\end{array}$ & $\begin{array}{l}P \\
\text { Value }\end{array}$ \\
\hline Age (years) & $58(22-78)$ & $60(18-84)$ & 0.372 \\
\hline \multicolumn{4}{|l|}{ Gender: } \\
\hline Male & $9(39 \%)$ & $8(40 \%)$ & \multirow[t]{2}{*}{0.954} \\
\hline Female & $14(61 \%)$ & $12(60 \%)$ & \\
\hline \multicolumn{4}{|l|}{ ASA risk classification } \\
\hline $\mathrm{I}-\mathrm{II}$ & $14(67 \%)$ & $14(74 \%)$ & \multirow[t]{2}{*}{0.736} \\
\hline III-IV & $7(33 \%)$ & $5(26 \%)$ & \\
\hline Body weight $(\%)^{\mathrm{a}}$ & $97(80-100)$ & $97(87-100)$ & 0.417 \\
\hline Duration of symptoms (wk) & $44(1-468)$ & $14(1-200)$ & 0.037 \\
\hline Diabetes mellitus & 2 & $4(20 \%)$ & 0.398 \\
\hline Cardiac disease & $7(30 \%)$ & $5(25 \%)$ & 0.708 \\
\hline COPD & 2 & 1 & 0.999 \\
\hline Albumin $<30 \mathrm{~g} / 1$ & 2 & 1 & 0.995 \\
\hline Creatinine $>150 \mathrm{mmol} / \mathrm{l}$ & $5(22 \%)$ & $2(10 \%)$ & 0.412 \\
\hline
\end{tabular}

Quantitative variables are given as median (range). A Fisher's exact test or a $\chi^{2}$ test was used for qualitative variables and a Mann-Whitney $U$ test for quantitative variables.

$A S A$ American Society of Anesthesiology, COPD chronic obstructive pulmonary disease

${ }^{a}$ Body weight as a percentage of pre-morbid body weight

One patient underwent interventional drainage for a retroperitoneal abscess after distal pancreatectomy with a pancreaticojejunostomy and left nephrectomy. The amylase concentration in the drain fluid measured less than $500 \mathrm{U} / 1$. No pancreatic fistula required an operative intervention; however, all four patients underwent interventional drainage. A 78-year-old female patient died from postoperative sepsis and multi-organ failure caused by an infected central venous line. The autopsy report revealed a vital and completely healed pancreatic

Table 2 Histology and Additional Surgical Procedures Performed in 43 Patients Undergoing Pancreatic Distal Resection

\begin{tabular}{lll}
\hline $\begin{array}{l}\text { Operative } \\
\text { Procedure }\end{array}$ & $\begin{array}{l}\text { Group 1 }(n=23) \text { (with } \\
\text { Pancreaticojejunostomy) }\end{array}$ & $\begin{array}{l}\text { Group 2 }(n=20) \\
\text { (No Anastomosis) }\end{array}$ \\
\hline $\begin{array}{l}\text { Histology } \\
\text { Pancreatic } \\
\text { neoplasms }\end{array}$ & $13(57 \%)$ & $14(70 \%)$ \\
$\begin{array}{l}\text { Other } \\
\text { neoplasms }\end{array}$ & $4(17 \%)$ & $3(15 \%)$ \\
$\begin{array}{l}\text { Chronic } \\
\text { pancreatitis }\end{array}$ & $5(22 \%)$ & $2(10 \%)$ \\
$\begin{array}{l}\text { Other } \\
\text { Procedures }\end{array}$ & 1 & 1 \\
$\begin{array}{l}\text { Splenectomy } \\
\text { Liver resection }\end{array}$ & $3(13 \%)$ & $18(90 \%)$ \\
Gastric & $3(13 \%)$ & $3(15 \%)$ \\
$\quad$ resection & $3(13 \%)$ & $2(10 \%)$ \\
Colon & & $2(10 \%)$ \\
$\quad$ resection & & 1 \\
Nephrectomy & $3(13 \%)$ & $2(10 \%)$ \\
Adrenalectomy & 2 & 0 \\
Necrosectomy & 1 & \\
\hline
\end{tabular}

anastomosis and no signs suggesting an intra-abdominal cause of sepsis.

Follow-up was completed in 41 patients (95\%). Two patients were lost to emigration. Median follow-up was 20 months (range 1-49), and mean survival was 33 months (95\% C.I. 29-43). No readmission occurred as a result of a postoperative pancreatic fistula. Follow-up morbidity was comparable between the two groups. A total of 9 patients $(29 \%)$ died because of recurrent malignant disease. Six patients were reoperated during follow-up: one patient underwent hepatic resection because of a recurrence of a neuroendocrine neoplasm; one patient required colon resection because of diverticulitis; and another patient underwent incisional hernia repair. The other three patients had extra-abdominal surgery. No patient required recurrent pancreatic surgery, and no patient who underwent pancreaticojejunostomy developed bowel obstruction. Fourteen patients $(32 \%)$ required insulin after pancreatic resection, and the incidence of pancreatogenic diabetes did not differ between the two groups. Enzyme supplementation was prescribed in 22 patients (51\%), and six patients (14\%) noted clinical signs of exocrine pancreatic insufficiency despite enzyme supplementation. The majority of patients could work or pursue their daily activities (75 and 66\%, respectively, for groups "anastomosis" and "oversewn").

\section{Discussion}

A pancreatic fistula according to a recently published classification is any measurable drainage on or after postoperative day 3 with an amylase content of more than 
Table 3 Postoperative Outcome (Frequency)

\begin{tabular}{|c|c|c|c|}
\hline Parameters & $\begin{array}{l}\text { Group } 1(n=23) \\
\text { (with Pancreaticojejunostomy) }\end{array}$ & $\begin{array}{l}\text { Group } 2(n=20) \\
\text { (No Anastomosis) }\end{array}$ & $\begin{array}{l}P \\
\text { Value }\end{array}$ \\
\hline \multicolumn{4}{|l|}{ Surgical morbidity } \\
\hline Pancreatic fistula & 0 & $4(20 \%)$ & 0.039 \\
\hline Bleeding & 1 & 1 & 0.995 \\
\hline Intra-abdominal abscess & $2^{\mathrm{a}}$ & $1^{\mathrm{b}}$ & 0.995 \\
\hline Biliary fistula & 0 & $1^{\mathrm{c}}$ & 0.465 \\
\hline Relaparotomy & 1 & 0 & 0.995 \\
\hline \multicolumn{4}{|l|}{ Nonsurgical morbidity ${ }^{\mathrm{d}}$} \\
\hline Cardiopulmonary & $6(26 \%)$ & $3(15 \%)$ & 0.087 \\
\hline Renal & 1 & $2(10 \%)$ & 0.590 \\
\hline Other & $4(13 \%)$ & $2(10 \%)$ & 0.561 \\
\hline Mortality & 1 & 0 & 0.995 \\
\hline
\end{tabular}

A Fisher's exact test or a $\chi^{2}$ test was used for qualitative variables and a Mann-Whitney $U$ test for quantitative variables.

${ }^{\text {a }}$ Including the one patient requiring reoperation for bleeding in this group

${ }^{\mathrm{b}}$ This patient also suffered from a pancreatic fistula

${ }^{\mathrm{c}}$ Related to a liver resection that was performed together with the pancreatic left resection

${ }^{\mathrm{d}}$ Systemic complications: cardiopulmonary, renal, sepsis, neural, others

three times the upper limit of serum amylase ${ }^{19}$. Three categories were defined: biochemical fistula without clinical sequelae (grade A); fistula requiring any therapeutic intervention (grade B); and fistula with severe clinical sequelae (grade C). Because the current study was begun in October 2001 and data were prospectively entered into a database, we did not use the new classification published in 2005. Retrospectively, all fistulas diagnosed in this paper were either grade $\mathrm{B}$ or grade $\mathrm{C}$. The definition used in this study is the same as that used in previous analyses of our patients $^{20,21}$ and is in accordance with other published series from high-volume centers ${ }^{3,22}$. Several different techniques were used for the treatment of the pancreatic stump after distal resection ${ }^{6,11-14,23}$. In a large single-center series of 235 pancreatic distal resections performed between 1994 and 1997, the incidence of postoperative pancreatic fistula was $5 \%{ }^{6}$. Others have reported a fistula rate of almost $30 \%{ }^{10}$ However, assessment of data from different centers is limited because of differences in fistula definition and patient heterogeneity, precluding unbiased comparison of outcomes. We therefore chose to perform a single-center study and compared results with our new technique with those from an earlier group of patients otherwise treated identically but without a pancreaticojejunal anastomosis.

Patient demographics were well comparable in our two groups of patients despite published data from other centers reporting changes in patient characteristics and indications for resection over time (increase in age and more resections for cystic lesions and fewer for chronic pancreatitis) ${ }^{24}$. In an earlier retrospective observational survey of 113 patients, 46 were treated with an additional pancreaticoenteric anastomosis, and no superiority of this technique was found. ${ }^{17}$ Adam et al. performed a pancreaticoenteric anastomosis in 27 of 41 patients undergoing distal pancreatic resection between 1994 and 2001. The anastomosis was associated with a leak-rate of $7 \%$ (2/27) compared to $29 \%$ (4/ $14)$ in the control group, but the difference did not reach the level of significance because of small sample size. ${ }^{18}$ In a prospective trial, 69 patients were randomly assigned to five treatment groups: suturing of the pancreatic stump, suturing and applying fibrin glue, suturing plus mesh, pancreaticojejunostomy, and stapler closure of the stump. The overall fistula rate was $19 \%$, ranging from 7 to $33 \%$, without a statistical advantage of one technique over the other. ${ }^{25}$

Besides technical reasons, the incidence of postoperative pancreatic fistula may also be influenced by the use of synthetic somatostatin analogues (octreotide, lanreotide, or vapreotide) and the texture of the gland. Three randomized trials evaluated the use of prophylactic octreotide in patients undergoing pancreaticoduodenectomy and found no benefit for the use of octreotide, as did a meta-analysis in 2002. ${ }^{22,26-28}$ On the other hand, four randomized, placebocontrolled, multicenter trials reported significant decreases in overall complication rates, and two of the four reported significantly lowered rates of pancreatic fistula in patients receiving prophylactic octreotide. Based on such data, our patients all received octreotide, which is also in accordance with a recent meta-analysis, demonstrating a reduction in the incidence of complications with the use of synthetic somatostatin analogs. ${ }^{29}$

Pancreatic texture and consistency were correlated with a risk of postoperative pancreatic fistula development. ${ }^{30}$ Partial resection of a fibrotic pancreas is associated with lower leak rates ( 0 to $5 \%$ ) compared to resection of a soft pancreas (20 to $25 \%$ ), while the incidence of a postoper- 
ative fistula in a pancreas with an intermediate consistency is 3 to $5 \%^{22}$.

Reoperation, septic complications with localized abscesses, and bleeding are other rare but important complications and indicators of surgical quality, having also a major impact on health-care resource consumption and economic outcome. ${ }^{2,31}$ In our series, there were three abscesses. However, the amylase concentration reached the level required for a pancreatic fistula only in the abscess in the patient from group 2 .

Because of different health-care systems, duration of hospital stay for a given intervention in Switzerland, in general, is greater than those reported in series from the US. Thus, in Switzerland, many complications are diagnosed during the initial hospital stay. Accordingly, there was no early readmission for either postoperative fistula or for abscess or bleeding. This outcome is in contrast to a recent paper from the US reporting on 56 patients with distal pancreatic resection of whom eight developed a pancreatic fistula grade $\mathrm{B}$ or C. Six of these eight patients were readmitted. ${ }^{32}$

The duration of hospital stay was similar in both groups in our study, suggesting that not only the presence or absence of a pancreatic fistula but also other factors, such as the cardiopulmonary or renal comorbidity that was evenly present in both groups, had a major impact on the duration of the hospital stay.

The additional operative effort of creating a Roux-en-Y limb and performing an anastomosis increased the duration of the operation only a short time, but did not reach statistical difference most likely because of the small number of patients studied.

\section{Conclusion}

This study may serve as an effort to evaluate Roux-en-Y drainage of the pancreatic stump after distal pancreatic resection. Further prospective randomized studies are needed to finally define the role of this technique in routine pancreatic left resection. Based on our results, a randomized trial would need 113 patients in each treatment arm to meet a power of $90 \%$ with a $5 \%$ two-sided significance level, assuming that a pancreatico-jejunostomy would modify the incidence of postoperative fistula after pancreatic distal resection by $15 \%$.

\section{References}

1. Balzano G, Zerbi A, Cristallo M, Di Carlo V. The unsolved problem of fistula after left pancreatectomy: the benefit of cautious drain management. J Gastrointest Surg 2005;9(6):837-842.

2. Rodriguez JR, Germes SS, Pandharipande PV, Gazelle GS,
Thayer SP, Warshaw AL, et al. Implications and cost of pancreatic leak following distal pancreatic resection. Arch Surg 2006;141(4): 361-366.

3. Sohn TA, Yeo CJ, Cameron JL, Koniaris L, Kaushal S, Abrams RA, et al. Resected adenocarcinoma of the pancreas - 616 patients: results, outcomes, and prognostic indicators. J Gastrointest Surg 2000;4(6):567-579.

4. Gouma DJ, van Geenen RC, van Gulik TM, de Haan RJ, de Wit LT, Busch OR, et al. Rates of complications and death after pancreaticoduodenectomy: risk factors and the impact of hospital volume. Ann Surg 2000;232(6):786-795.

5. Alexakis N, Halloran C, Raraty M, Ghaneh P, Sutton R, Neoptolemos JP. Current standards of surgery for pancreatic cancer. Br J Surg 2004;91(11):1410-1427.

6. Lillemoe KD, Kaushal S, Cameron JL, Sohn TA, Pitt HA, Yeo CJ. Distal pancreatectomy: indications and outcomes in 235 patients. Ann Surg 1999;229(5):693-700.

7. Adam U, Makowiec F, Riediger H, Benz S, Liebe S, Hopt UT. Pancreatic leakage after pancreas resection. An analysis of 345 operated patients. Chirurg 2002;73(5):466-473.

8. Mabrut JY, Fernandez-Cruz L, Azagra JS, Bassi C, Delvaux G, Weerts J, et al. Laparoscopic pancreatic resection: results of a multicenter European study of 127 patients. Surgery 2005;137 (6):597-605.

9. Fernandez-Cruz L, Martinez I, Gilabert R, Cesar-Borges G, Astudillo E, Navarro S. Laparoscopic distal pancreatectomy combined with preservation of the spleen for cystic neoplasms of the pancreas. J Gastrointest Surg 2004;8(4):493-501.

10. Okabayashi T, Kobayashi M, Sugimoto T, Okamoto K, Matsuura $\mathrm{K}$, Araki K. Postoperative pancreatic fistula following surgery for gastric and pancreatic neoplasm; is distal pancreaticosplenectomy truly safe? Hepatogastroenterology 2005;52(61):233-236.

11. Ohwada S, Ogawa T, Tanahashi Y, Nakamura S, Takeyoshi I, Ohya $\mathrm{T}$, et al. Fibrin glue sandwich prevents pancreatic fistula following distal pancreatectomy. World J Surg 1998;22(5):494-498.

12. Konishi T, Hiraishi M, Kubota K, Bandai Y, Makuuchi M, Idezuki Y. Segmental occlusion of the pancreatic duct with prolamine to prevent fistulas following distal pancreatectomy. Ann Surg 1995; 221:165-170.

13. Rieger R, Wayand W. Pancreas resection with the surgical stapler. Technique and results. Chirurg 1995;66(1):54-58.

14. Suc B, Msika S, Fingerhut A, Fourtanier G, Hay JM, Holmieres $\mathrm{F}$, et al. Temporary fibrin glue occlusion of the main pancreatic duct in the prevention of intra-abdominal complications after pancreatic resection: prospective randomized trial. Ann Surg 2003;237(1):57-65.

15. Knaebel HP, Diener MK, Wente MN, Buchler MW, Seiler CM. Systematic review and meta-analysis of technique for closure of the pancreatic remnant after distal pancreatectomy. Br J Surg 2005;92 (5):539-546.

16. Andren-Sandberg A, Wagner M, Tihanyi T, Loefgren P, Friess H. Technical aspects of left-sided pancreatic resection for cancer. Dig Surg 1999;16:305-312.

17. Shankar S, Theis B, Russell RC. Management of the stump of the pancreas after distal pancreatic resection. Br J Surg 1990;77 (5):541-544.

18. Adam U, Makowiec F, Riediger H, Trzeczak S, Benz S, Hopt UT. Distal pancreatic resection-indications, techniques and complications. Zentralbl Chir 2001;126(11):908-912.

19. Bassi C, Dervenis C, Butturini G, Fingerhut A, Yeo C, Izbicki J, et al. Postoperative pancreatic fistula: an international study group (ISGPF) definition. Surgery 2005;138(1):8-13.

20. Buchler MW, Friess H, Wagner M, Kulli C, Wagener V, Z'Graggen K. Pancreatic fistula after pancreatic head resection. Br J Surg 2000;87(7):883-889.

21. Buchler MW, Wagner M, Schmied BM, Uhl W, Friess H, Z'Graggen 
K. Changes in morbidity after pancreatic resection: toward the end of completion pancreatectomy. Arch Surg 2003;138(12):1310-1315.

22. Yeo CJ, Cameron JL, Lillemoe KD, Sauter PK, Coleman J, Sohn TA, et al. Does prophylactic octreotide decrease the rates of pancreatic fistula and other complications after pancreaticoduodenectomy? Results of a prospective randomized placebo-controlled trial. Ann Surg 2000;232(3):419-429.

23. Rodriguez JR, Razo AO, Wargo JA, Thayer SP, Warshaw AL, Fernandez del-Castillo C. Reduction in pancreatic leak following distal pancreatectomy - a novel technique utilizing an autologous falciform patch. Gastroenterology 2006;130(Suppl 2):A 887.

24. Balcom JHt, Rattner DW, Warshaw AL, Chang Y, Fernandez-del Castillo C. Ten-year experience with 733 pancreatic resections: changing indications, older patients, and decreasing length of hospitalization. Arch Surg 2001;136(4):391-398.

25. Bassi C, Butturini G, Falconi M, Salvia R, Sartori N, Caldiron E, et al. Prospective randomized pilot study of management of the pancreatic stump following distal resection. HPB Surg 1999;1 (4):203-207.

26. Poon RT, Lo SH, Fong D, Fan ST, Wong J. Prevention of pancreatic anastomotic leakage after pancreaticoduodenectomy. Am J Surg 2002;183(1):42-52.
27. Lowy AM, Lee JE, Pisters PW, Davidson BS, Fenoglio CJ, Stanford $\mathrm{P}$, et al. Prospective, randomized trial of octreotide to prevent pancreatic fistula after pancreaticoduodenectomy for malignant disease. Ann Surg 1997;226(5):632-641.

28. Hesse UJ, DeDecker C, Houtmeyers P, Demetter P, Ceelen W, Pattyn $\mathrm{P}$, et al. Prospectively randomized trial using perioperative low-dose octreotide to prevent organ-related and general complications after pancreatic surgery and pancreatico-jejunostomy. World J Surg 2005;29(10):1325-1328.

29. Connor S, Alexakis N, Garden OJ, Leandros E, Bramis J, Wigmore SJ. Meta-analysis of the value of somatostatin and its analogues in reducing complications associated with pancreatic surgery. Br J Surg 2005;92(9):1059-1067.

30. Alexakis N, Sutton R, Neoptolemos JP. Surgical treatment of pancreatic fistula. Dig Surg 2004;21(4):262-274

31. Tien YW, Lee PH, Yang CY, Ho MC, Chiu YF. Risk factors of massive bleeding related to pancreatic leak after pancreaticoduodenectomy. J Am Coll Surg 2005;201(4):554-559.

32. Pratt W, Maithel S, Vanounou T, Callery MP, Vollmer CM. Postoperative pancreatic fistulas are not equivalent after proximal, distal and central pancreatectomy. J Gastrointest Surg 2006;10 (9):1264-1279. 